https://doi.org/10.26694/caedu.v3i1. 10997

ISSN 2675-1496

\title{
Duas mulheres educadas no oitocentos: registros em egodocumentos femininos
}

\author{
Two women educated int he eighties: records in \\ female egodocuments
}

Maria Celi Chaves Vasconcelos (iDa

AnA CRIStina B. Lopez M. FRAnCisco (D)

\begin{abstract}
Resumo:
A partir da análise dos arquivos pessoais e egodocumentos elaborados por duas mulheres que viveram no Brasil, no século XIX, o objetivo central do presente trabalho é evidenciar o que essas fontes podem nos dizer sobre a vida dessas mesmas mulheres, em um contexto patriarcal, escravocrata e que reservava a elas um papel social limitado, além de submetido a constante vigilância. Os procedimentos metodológicos tratam de uma pesquisa qualitativa, utilizando como fontes de investigação diferentes categorias documentais, sobretudo, o inventário de cartas e diários que guardam marcas da história dessas mulheres e o posterior exame detalhado desses registros. Conclui-se que, apesar de egodocumentos, sob a forma, especialmente, de diários, serem raros em nosso país, contribuindo para o silenciamento feminino, ainda é possível localizar alguns como os objetos de nossa investigação, que permitem perpetuar a memória de mulheres há muito esquecidas, demonstrando o seu cotidiano envolto a preocupações relativas às funções femininas de gestoras da casa, esposas e mães. Como demonstram os registros estudados, a educação recebida visava, especialmente, a preparação para o casamento, para gerir a casa e cuidar dos filhos. Igualmente, a proximidade com as elites imperiais exigia o domínio dos padrões comportamentais franceses, particularmente, para quem frequentava a Corte brasileira, situada na cidade do Rio de Janeiro, e para quem convivia com os membros da realeza.
\end{abstract}

Palavras-chave:

Egodocumentos; Arquivos femininos; Escritas pessoais; Cartas e Diários; Brasil Império.

\footnotetext{
a Universidade do Estado do Rio de Janeiro, Brasil. Programa de Pós-Graduação em Educação Proped- Verj. maria2.celi@gmail.com . ORCID http://orcid.org/0000-0002-3624-4854

b Universidade do Estado do Rio de Janeiro, Brasil. Curso de Pedagogia a Distância Cederj/Uerj acblmf@gmail.com. ORCID https://orcid.org/0000-0002-11 114-0565
}

Rev. Caminhos da Educação: diálogos, culturas e diversidades, Teresina, v. 2, n. 1, p.109-123, mai./ago. 2020 


\begin{abstract}
:
Based on the analysis of the personal files and the egodocuments prepared by two women who lived in Brazil in the 19th century, the main objective of this work is to highlight what these sources can tell us about the lives of these same women, in a patriarchal context, slavery and that they reserved a limited social role for them, in addition to being subject to constant vigilance. The methodological procedures deal with qualitative research, using different categories of documents as sources of research, especially the inventory of letters and diaries that maintain marks of the history of these women and the subsequent detailed examination of these records. It is concluded that, although egodocuments, especially in the form of newspapers, are rare in our country, contributing to feminine silencing, it is still possible to locate some as objects of our research, which allow us to perpetuate the memory of women, much forgotten, demonstrating her daily life involved with concerns related to the female roles of home managers, wives and mothers. As the records studied, the education received was especially geared toward preparing for marriage, managing the home, and caring for children. Similarly, proximity to imperial elites required mastery of French behavior patterns, particularly for those who attended the Brazilian Court, located in the city of Rio de Janeiro, and for those who lived with royalty.
\end{abstract}

\title{
Keywords:
}

Egodocuments; Female archives; Personal writings; Letters and diaries; Empire of Brazil.

\begin{abstract}
Resumen:
Basado en el análisis de los archivos personales y en los egodocumentos preparados por dos mujeres que vivieron en Brasil en el siglo XIX, el objetivo principal del presente trabajo es resaltar lo que estas fuentes pueden decirnos sobre la vida de estas mismas mujeres, en un contexto patriarcal, esclavitud y que reservaron un rol social limitado para ellos, además de estar sujetos a vigilancia constante. Los procedimientos metodológicos se ocupan de una investigación cualitativa, utilizando diferentes categorías de documentos como fuentes de investigación, sobre todo, el inventario de cartas y diarios que mantienen marcas de la historia de estas mujeres y el posterior examen detallado de estos registros. Se concluye que, aunque los egodocumentos, en la forma, especialmente, de diarios, son raros en nuestro país, contribuyendo al silenciamiento femenino, todavía es posible localizar algunos como objetos de nuestra investigación, que permiten perpetuar la memoria de las mujeres, muy olvidadas, demostrando su vida diaria involucrada con preocupaciones relacionadas con los roles femeninos de las administradoras de casa, esposas y madres. Como muestran los registros estudiados, la educación recibida estaba dirigida especialmente a prepararse para el matrimonio, administrar el hogar y cuidar a los niños. Del mismo modo, la proximidad a las élites imperiales requirió el dominio de los patrones de comportamiento franceses, particularmente para aquellos que asistieron a la Corte brasileña, ubicada en la ciudad de Río de Janeiro, y para aquellos que vivían con la realeza.
\end{abstract}

Palabras clave:

Egodocumentos; Archivos femeninos; Escritos personales; Cartas y diarios; Imperio de Brasil.

Rev. Caminhos da Educação: diálogos, culturas e diversidades, Teresina, v. 2, n. 1, p.109-123, mai./ago. 2020 
Duas mulheres educadas no oitocentos: registros em egodocumentos femininos

\title{
Introdução
}

De acordo com o teórico alemão Winfried Schulze (1996), o termo Ego-Dokumente inclui todas as fontes em que um indivíduo expõe informações sobre si mesmo, independentemente dessa ação ser realizada voluntariamente, por exemplo, em uma carta, um diário, um sonho ou uma transcrição autobiográfica. A concepção de egodocumentos citada por Fulbrook e Rublack (2010), assinala que eles são fundamentais na construção de biografias individuais pelas pistas que apresentam expressa ou implicitamente, como desejos, preconceitos, ambições, e assim por diante.

Os egodocumentos como diários pessoais femininos são uma categoria bastante rara (Freyre, 1997), especialmente tratando-se do século XIX, no Brasil, quando as limitações às mulheres incluíam a censura aos escritos daquelas que eram letradas e que, normalmente, pertenciam às camadas mais altas da população (Bollmann, 2011 a). Tal censura visava preservá-las para o casamento e evitar que por meio de bilhetes e cartas fossem estabelecidos laços afetivos, contrariando os desígnios da família (Bollmann, $2011 b)$. No intuito de burlar essa vigilância eram estabelecidos códigos, alguns baseados em cores, flores, movimentos com o lenço ou leque, entre outros, bastante populares no círculo das moças e rapazes oitocentistas, e que, de alguma forma, substituíam a escrita.

Num contexto de extrema vigilância dos pais, o diário íntimo, portanto, não era a principal escolha das moças casadoiras para externar seus sentimentos ou registrar sua rotina, hipótese essa que, talvez, explique a raridade desse tipo de fonte nos acervos brasileiros.

Assim, encontrar um diário feminino oitocentista preservado e estudá-lo é a possibilidade de um contato singular com o cotidiano feminino de um passado distante há mais de um século, cuja memória não pode ser totalmente preservada, justamente pela falta de registros escritos femininos. O próprio Gilberto Freyre (1997) corrobora essa raridade quando, na amplitude e na complexidade de suas pesquisas sobre o oitocentos, não logrou localizar um sequer exemplar:

\begin{abstract}
Aqui o confessionário absorveu os segredos pessoais e de família, estancando nos homens, e principalmente nas mulheres, essa vontade de se revelarem aos outros que nos países protestantes provê o estudioso de história íntima de tantos diários, confidências, cartas, memórias, autobiografias, romances autobiográficos. Creio que não há no Brasil um só diário escrito por mulher. Nossas avós, tantas delas analfabetas, mesmo quando baronesas e viscondessas satisfaziam-se em contar os segredos ao padre confessor e à mucama de estimação; e a sua tagarelice dissolveu-se quase toda nas conversas com as pretas boceteiras, nas tardes de chuva ou nos meios-dias quentes, morosos. Debalde se procuraria entre nós um diário de dona de casa cheio de gossip no gênero dos ingleses e dos norteamericanos dos tempos coloniais (Freyre, 1997, p. XVI).
\end{abstract}

No que se refere às cartas escritas por mulheres oitocentistas, embora não sejam tão raras como os diários, também não há em nossos acervos brasileiros muitos manuscritos Rev. Caminhos da Educação: diálogos, culturas e diversidades, Teresina, v. 2, n. 1, p.109-123, mai./ago. 2020 
desse tipo de memória escrita preservada. Isto ocorre pelas mesmas razões afeitas ao diário íntimo, acrescidas do fato que poucas mulheres liam e escreviam, sendo este um diferencial da condição feminina das elites aristocráticas e, portanto, única camada da população na qual é possível a localização de egodocumentos dessa natureza (Bollmann, 201 1a, 201 lb). Além disso, quanto mais nobre, ou dependendo do lugar que se ocupasse na hierarquia da Corte brasileira, maiores as chances de que os documentos pessoais femininos fossem preservados, especialmente, as cartas trocadas entre pessoas ilustres da época.

Nessa perspectiva, o presente estudo tem como objetivo central analisar aspectos da educação feminina, a partir da investigação de egodocumentos produzidos por duas mulheres que faziam parte da aristocracia brasileira, notadamente, mulheres leitoras $e$ escritoras que viveram no século XIX. A principal fonte para a operação historiográfica realizada são os arquivos pessoais dessas mulheres, diários e cartas, produzidos tanto de forma involuntária, quanto para o registro das memórias vividas, reunidos em um banco de dados, que chamamos de "inventário" de egodocumentos. Ambas são mulheres inseridas no contexto do Rio de Janeiro oitocentista, portanto, em um período em que, segundo Michele Perrot (2005), além de silenciadas, sofriam o constante controle dos pais, mães, pároco, avós, enfim de uma rede de "protetores", cuja principal missão era deixá-las "imaculadas" para o casamento.

A problemática que se constitui na questão central do trabalho é, portanto, a partir dos arquivos pessoais e egodocumentos escritos por mulheres, evidenciar o que essas fontes podem nos dizer sobre a vida dessas mesmas mulheres, em um contexto brasileiro patriarcal, escravocrata e que reservava a elas um papel social limitado, além de submetido a constante vigilância.

As mulheres que elegemos para a pesquisa com egodocumentos são duas protagonistas contemporâneas em seu período de vida e em sua condição de nobres pertencentes à aristocracia brasileira. São elas, a condessa de Barral e a viscondessa do Arcozelo, ambas partícipes dos caminhos e descaminhos que marcaram o apogeu e o declínio do Segundo Reinado no Brasil (1840-1889).

\section{Metodologia e fontes com egodocumentos}

Os procedimentos metodológicos tratam de uma pesquisa qualitativa, utilizando como fontes de investigação diferentes categorias documentais, sobretudo, o inventário de cartas e diários que guardam marcas da história dessas mulheres que viveram no século XIX. Dessa forma, foi realizado o exame detalhado de egodocumentos pertencentes as duas mulheres nobres, tendo como principais fontes os arquivos pessoais ainda preservados. Tais fontes são analisadas desde a sua localização, catalogação e conteúdo, priorizando informações acerca do cotidiano e da educação dessas mulheres.

Seguindo a trilha dos egodocumentos produzidos por elas, nossa pesquisa iniciou pela visita a uma grande quantidade de casas de guarda e patrimônio, das quais se destacam, no Rio de Janeiro, o Arquivo Nacional, a Biblioteca Nacional, o Arquivo Geral da cidade do Rio de Janeiro, o Real Gabinete Português de Leitura, o Museu Histórico Nacional, o Instituto Histórico Geográfico Brasileiro do Rio de Janeiro e, em Petrópolis, o Museu Imperial, nos arquivos da Casa Imperial, o Instituto Histórico de Petrópolis e a Biblioteca Municipal Gabriela Mistral. Analisando uma extensa profusão de arquivos existentes nessas instituições, foi possível localizar os documentos que buscávamos, entre eles, os arquivos pessoais que continham informações sobre essas mulheres, bem como egodocumentos preservados.

No que se refere à condessa de Barral, Luiza Margarida Portugal de Barros, nascida na Bahia, em 1816, as fontes são, sobremaneira, mais vastas por se tratar da preceptora

Rev. Caminhos da Educação: diálogos, culturas e diversidades, Teresina, v. 2, n. 1, p.109-123, mai./ago. 2020 
Duas mulheres educadas no oitocentos: registros em egodocumentos femininos

das princesas Isabel e Leopoldina, filhas de d. Pedro II e herdeiras do trono do Brasil. Além das instituições já citadas, nas quais há acervos dedicados a registros da condessa de Barral, no decurso do tempo, alguns pertences da condessa, como quadros e diários, foram adquiridos por particulares em leilões e doados ou vendidos, posteriormente. Alguns se encontram em São Paulo, na biblioteca da Universidade de São Paulo, na qual estão guardados 29 dos seus diários e o único quadro conhecido de Luiza, ainda criança, está na Fundação Maria Luisa e Oscar Americano.

Como existem muitos documentos em arquivos pessoais e egodocumentos pertencentes à condessa de Barral, optamos pela ideia de Hilsdorf (1999), registrando, a princípio, toda sorte de informações sobre locais, autores, proprietários, editores e instituições, elaborando um "inventário" das fontes, pretendendo que o mesmo fosse o mais completo possível. A importância desse inventário preliminar se constituiu na medida da necessidade de se ter uma visão do conjunto dos documentos e informações espalhados por vários acervos, instituições e museus do país.

Dialogando com autores que também se depararam com uma grande quantidade de documentos em suas pesquisas qualitativas, alguns passos foram delineados para a seleção das fontes dos egodocumentos da condessa de Barral. Heymann (2012), ao analisar o volume e a complexidade da documentação reunida no arquivo pessoal do seu objeto de estudo, buscou avançar na relativização e na associação entre conjuntos documentais de natureza pessoal e memória individual. Para tanto, ela desloca 0 arquivo da posição de "campo" de pesquisa para a de "informante" privilegiado do campo institucional em que se localiza e que the confere inteligibilidade.

Nessa mesma linha, analisando a construção do inventário do patrimônio religioso paraibano, Rocha (2011) considera o inventário uma fonte inesgotável de informação, como fonte e como meio, possibilitando agregar novos usos, significados, valores, tendo como base a informação para a compreensão dos processos histórico, social, econômico e cultural de um determinado tempo e tempo-espaço. A contribuição teórico-metodológica do inventário é especialmente relevante para uma visão do conjunto do patrimônio e para sua categorização e acesso pela sociedade. Assim, para trabalhar os arquivos pessoais relativos à condessa de Barral optou-se pela utilização da categoria inventário de fontes, documentos e, particularmente, egodocumentos, considerando a quantidade de arquivos disponíveis.

Com relação a nossa outra protagonista, que viveu uma existência mais anônima, sob - ponto de vista da notoriedade em seu tempo, embora fosse uma perfeita representante da elite imperial, filha e neta de barões do café, não foi possível encontrar uma ínfima parte do material documental semelhante ao da condessa de Barral. Sua vida dedicada aos filhos, ao marido e à gestão da casa e de suas fazendas de café, com seus escravizados, fez com que apenas um egodocumento fosse capaz de preservar sua memória do completo esquecimento. Trata-se de um egodocumento extremamente singular por sua autoria e contexto: o Diário de Lembranças da viscondessa de Arcozelo, Maria Isabel de Lacerda Werneck, uma mulher nascida no século XIX, no ano de 1840, que viveu o apogeu do Império do Brasil, bem como a sua decadência que culminou com a mudança da ordem política vigente.

Trabalhando com uma quantidade significativa de dados, coletados a partir das fontes dos egodocumentos inventariados, foi necessário utilizar os recursos oferecidas pela

Rev. Caminhos da Educação: diálogos, culturas e diversidades, Teresina, v. 2, n. 1, p.109-123, mai./ago. 2020 
internet, a fim de tornar exequível aquilo que as autoras Samara e Tupy (2010, p. 129) afirmam: "o computador tornou viável, graças à digitalização de textos e imagens, bem como ao armazenamento e cruzamento de dados, a possibilidade de análise com números bem mais elevados de variáveis". Assim, seguindo a recomendação das autoras (Samara \& Tupy), aglutinamos e armazenamos as informações através da criação de um banco de dados, visando a facilitar o trabalho empírico com esse tipo de pesquisa qualitativa, baseada em fontes essencialmente de egodocumentos. Esse método auxiliou na elaboração de teorias que justificassem a especificidade ou não dos dados encontrados e ainda, viabilizassem análises entre os diversos conjuntos de inventários pesquisados.

Após a realização do inventário, da digitalização e da catalogação dos egodocumentos pertencentes à condessa de Barral e à viscondessa de Arcozelo, em especial no seu papel de mulheres educadas nos padrões do que havia de melhor no seu tempo, foi necessário buscar referenciais metodológicos capazes de nortear uma investigação qualitativa eminentemente bibliográfica e documental.

Assim, o estudo apresentado está fundamentado em procedimentos inerentes a uma pesquisa qualitativa histórico-documental, cujas fontes, para além dos egodocumentos investigados, relativos ao inventário de cartas e diários, que guardam marcas da história dessas mulheres, também incluem registros de pessoas que conviveram com elas, a análise de bibliografia sobre mulheres oitocentistas, teses e dissertações sobre o tema, publicações locais e estrangeiras, iconografia e literatura da época, documentos oficiais, jornais e revistas periódicas.

Segundo Burke (1992), quando se começa a fazer questionamentos acerca do passado, para a escolha de novos objetos de pesquisa, tem-se que buscar também outros tipos de fontes, para suplementar os documentos oficiais. É nesse sentido que o estudo dos egodocumentos torna-se uma forma de dar voz a uma infinidade de outros tipos de fontes.

Assim, para compor o inventário relativo aos arquivos pessoais da condessa de Barral, foram incluídos livros pertencentes a ela, cartas recebidas, iconografia, documentos como cadernos, boletins e planos de aula, além de objetos pessoais que estão sob a guarda de Instituições e da família.

Tendo em vista a grande quantidade de fontes, a elaboração do inventário foi realizada em uma ordem cronológica e de pertencimento às Instituições de patrimônio visitadas, listando seus arquivos e acervos. Para tanto, foram elaborados quadros por categoria documental, demonstrando o que foi inventariado em cada Instituição/Acervo/Arquivo consultado.

A partir do inventário, iniciamos o estudo dos egodocumentos, elegendo especialmente as cartas, tendo em vista que foram as fontes mais numerosas. Tratam-se de missivas pessoais e epístolas escritas e recebidas pela condessa. Na tentativa de analisar as fontes epistolares e no intuito de entender melhor as informações contidas em algumas cartas e documentos, foi necessário confrontá-las aos diários dos membros da Família Imperial, aos diários da própria condessa de Barral, aos diários da baronesa de Loreto (amiga da condessa), às anotações do mordomo da Casa Imperial, a legislações, bem como a todo o material concernente à educação das princesas brasileiras disponível no Museu Imperial.

O Museu Imperial em Petrópolis possui em seu acervo várias cartas e documentos catalogados sob a sigla "DBM", que significa Coleção Barral Monferrat; "APB" Arquivo Paulo Barbosa; e "AGP" Arquivo Grão-Pará, contendo desde o contrato de Luiza para ser a preceptora das princesas imperiais brasileiras, até epístolas trocadas entre ela e o imperador d. Pedro II, assim como com as princesas Isabel e Leopoldina. O acervo pertence à Família Imperial que o cedeu ao Museu Imperial, em forma de comodato, para que esses documentos estivessem disponíveis para pesquisadores.

Rev. Caminhos da Educação: diálogos, culturas e diversidades, Teresina, v. 2, n. 1, p.109-123, mai./ago. 2020 


\section{Duas mulheres educadas no oitocentos: registros em egodocumentos femininos}

Entre os aspectos materiais estudados nas missivas estão o papel, a tinta, o envelope, bem como outros elementos de igual significação (como desenhos, selos, recortes), que precisam de análise cuidadosa (Blas, 2003). Algumas cartas, pelo declínio do tempo e por terem ficado sem os cuidados necessários para que não se deteriorassem, acabaram por sofrer expressivo desgaste do papel, o que dificulta bastante à análise e o estudo de seu conteúdo.

Com centenas de epístolas sobre os mais diversos assuntos e endereçadas a diferentes destinatários, tornou-se necessário fazer um recorte delimitando o estudo ao inventário das cartas que fazem parte do acervo familiar e que poderiam ser lidas como egodocumentos contendo informações pessoais sobre a condessa. O conteúdo das cartas foi catalogado, classificando-as por datas, locais, destinatários e remetentes e cruzando-as para a obtenção de informações complementares às lacunas verificadas.

No que se refere à pesquisa com o Diário de Lembranças da viscondessa de Arcozelo, como se tratava de uma única fonte documental, a operação historiográfica tornou-se mais específica, mas nem por isso mais limitada. No caso da viscondessa, o diário suscita muitas questões e, a priori, demonstra aspectos singulares da vida dessa mulher, como o próprio hábito de fazer um registro do cotidiano, quando essa não era uma prática comum às mulheres nobres da Província fluminense, ou pelo menos, como afirma Michelle Perrot (2005, p.90) "tais diários não são raros; mas eles chegam apenas excepcionalmente ao público. Seus autores - mulheres, na maior parte das vezes - os destroem geralmente na chegada de sua velhice, preocupados em não se expor ao olhar indiferente ou irônico de seus herdeiros".

A fim de recompor fragmentos autobiográficos contidos no diário investigado, o primeiro procedimento metodológico utilizado neste estudo, buscou indagar o egodocumento, como sugere Henrique (2009, p.12): "Como tratar um diário íntimo? Como se posicionar diante do 'efeito de verdade' que esse tipo de documento produz? Quais leituras um diário íntimo nos permite? É possível compreendê-lo para além do indivíduo que escreve? O que motiva alguém a escrever um diário íntimo?". Ainda o mesmo autor lança uma pista do caminho a ser seguido: "As entradas feitas no diário permitem múltiplas abordagens. Os temas são muito variados, razão pela qual é preciso fazer um recorte que conduza a pesquisa" (Henrique, 2009, p.14). Nesse caso, para a pesquisa qualitativa no diário da viscondessa, optou-se por centrar as análises nas possibilidades de leitura que o egodocumento permite em relação a sua protagonista, não desconsiderando a materialidade desse objeto, semelhante a um caderno impresso ou uma agenda moderna, com as informações que ele tem para oferecer (Vasconcelos, 2014).

Observa-se, ainda, o que Cunha (2000) recomenda como o papel do historiador diante de um documento que admite inúmeras incursões,
Os diários têm funcionado como preciosa fonte para um certo conhecimento das maneiras de viver, das ideias circulantes, dos signos, dos códigos comportamentais de determinada época, um dispositivo textual que permite também entrever os imaginários de seus a(u)tores sociais. Expondo dúvidas, mil nadas, fragmentos da memória pessoal, familiar e grupal de seu tempo, o trabalho com esse material torna possivel dar visibilidade ao que estava destinado ao silêncio e ao esquecimento (Cunha, 2000, p. 160).

Rev. Caminhos da Educação: diálogos, culturas e diversidades, Teresina, v. 2, n. 1, p.109-123, mai./ago. 2020 
Tendo em conta as dificuldades em traçar um caminho linear para análises que envolvem tamanhas subjetividades, a investigação adotou, no percurso metodológico da pesquisa qualitativa, elementos afeitos ao método biográfico, especialmente no que se refere a sua perspectiva interacionista para captar essas subjetividades, compreendendo que "a conduta é continuamente remodelada" (Digneffe, 1997, p. 208), para atender, também, as expectativas dos outros, que obrigam a certa objetividade na experiência vivida.

Dessa forma, numa articulação imbricada entre objeto e fonte, os arquivos pessoais estudados que contêm egodocumentos pertencentes à condessa de Barral e à viscondessa de Arcozelo foram investigados com o pressuposto que cada pessoa é uma síntese do seu tempo histórico e, portanto, a pesquisa qualitativa aplicada a um objeto é capaz de oferecer elementos para a elucidação de outras circunstâncias semelhantes.

\title{
As protagonistas e suas histórias
}

A condessa de Barral foi, possivelmente, a mais influente preceptora brasileira na Corte Imperial do Segundo Reinado, tendo sido escolhida para reger e educação das princesas brasileiras. Seus principais escritos preservados são cartas trocadas com a Família Imperial brasileira, nas quais dá notícias da evolução da formação das princesas Isabel e Leopoldina, de quem era "aia", mas também trata de outros assuntos envolvendo, por vezes, até mesmo questões de estado.

A princesa Isabel, então com 10 anos de idade, faz uma anotação em seu diário, em 09 de setembro de 1856: "Veio hoje, pela primeira vez, minha aia a Condessa de Barral, e dei com ela princípio ao estudo da língua francesa, dei lição de piano". Ainda registrando seu cotidiano junto à condessa, no dia 20 de novembro de 1856, escreve: "Não fui passear, porque dei a minha primeira lição de dansa".

Sobre a função de preceptora da condessa de Barral, um dos seus biógrafos, Magalhães Junior (1956), escreve que o artigo publicado na Revista Popular, volume X, no ano 1861, intitulando uma gravura com A Augusta Família Imperial, trazia o seguinte texto:

\begin{abstract}
Pai extremoso, vela (o imperador) com o maior cuidado sobre a educação da sua prole, sabendo, como profundo filósofo, que esta é a mais bela herança que Ihe pode deixar. Como outrora Felipe de Alexandria, que se felicitava que Ihe nascesse um filho em tempo de ser discípulo de Aristóteles, folgov o Imperador em encontrar na senhora Condessa de Barral uma hábil preceptora, que com raro talento forma o coração das jovens princesas (Magalhães Junior, 1956, p. 15).
\end{abstract}

Del Priore (2008, p. 13) atribuiu à condessa de Barral o adjetivo de ter sido uma "camaleoa". Luiza Margarida demonstrou adaptar-se aos vários ambientes que frequentou, desde as Cortes de reis, na França de Luís Filipe, ao Rio de Janeiro e Petrópolis de D. Pedro Il; até a Província da Bahia e aos seus engenhos no Recôncavo (Pinho, 1959). Certo é que a condessa de Barral, além de responsável pela educação das princesas, tornou-se, cada vez mais, membro atuante e indispensável nas questões relativas à Corte brasileira, além de ter uma imensa influência sobre a herdeira do trono, Isabel, e o Imperador.

Dessa forma, estava sempre presente junto às princesas e, concluída a educação delas, permaneceu com a mesma intimidade com o soberano, viajando com a Família Imperial e recebendo-a em suas residências na Europa. De acordo com nosso outro estudo (Vasconcelos \& Francisco, 2014), os diários de viagens da condessa de Barral trazem informações, meticulosamente anotadas, de todos os itinerários em que acompanhou a Família Imperial, com os compromissos que foram cumpridos, as compras realizadas e algumas observações sobre as pessoas presentes nas visitas e

Rev. Caminhos da Educação: diálogos, culturas e diversidades, Teresina, v. 2, n. 1, p.109-123, mai./ago. 2020 
Duas mulheres educadas no oitocentos: registros em egodocumentos femininos

contra visitas, especialmente, as mais importantes, quando se tratava de reis e rainhas, como no caso da rainha Vitória, recebida por ela e registrada no diário em 05 de julho de 1871.

Pinho (1959, p. 175) afirma que nenhuma mulher daquela época teve igual poder social e político. Em meio a tantas damas da época, sobressaía a Barral, "a servir um espírito vivo e culto, desembaraçado e sagaz, que captava como um imã, e impunha suavemente como uma onda que se desenrola e domina". Suas cartas demonstram parte deste "espírito", mas, principalmente, denotam a abrangência de sua influência na Corte do Segundo Reinado brasileiro, tornando o seu pensamento sobre a "boa" educação feminina, o ideal a ser buscado pelas famílias da aristocracia, até que a República silenciasse sua memória como preceptora das princesas, atribuindo a ela outro papel, bem menos nobre, na história oitocentista.

A história da vida de Maria Isabel de Lacerda Werneck, coincidentemente ou propositadamente, devido à inserção de sua família no "modus vivendi" do Império, acompanha esse mesmo percurso de apogeu, durante o qual a viscondessa chegou a possuir em suas fazendas "mil escravos" (Castro, 2004, p. 119), e declínio, quando um dos seus filhos chega ao "extremo de ficar sem teto" (Castro, 2004, p. 118).

Em que pese à importância da investigação das condições políticas, econômicas e sociais que levaram a transformação completa das circunstâncias ao longo da existência desses antigos nobres da Província fluminense, nesse estudo nosso foco são os egodocumentos produzidos por essas mulheres, e o que é possível recompor de suas vidas a partir de seus registros pessoais.

A viscondessa de Arcozelo, por sua vez, registrou em seu Diário de Lembranças, datado do ano de 1887, um cotidiano comum às mulheres nobres do seu tempo. Provavelmente, ela escrevia cotidianamente, contando, de forma pormenorizada, a rotina dos seus dias passados, principalmente, nas fazendas de propriedade da família.

Caso fossemos hierarquizar a temática das anotações realizadas pela viscondessa em seu diário, de maneira especial aparecem os registros relativos à família e à rede de sociabilidade mantida por meio das visitas que recebia e retribuía, à gestão das três fazendas e de seus escravos, escravas e ingênuos, com particular ênfase à realização de listas de seus pertences, como louças, costuras, encomendas e despesas, além das condições meteorológicas descritas cotidianamente. Assim, pode-se afirmar que essas eram as principais preocupações que preenchiam os dias dessa mulher nobre, exímia representante da aristocracia cafeeira.

Em grande parte das páginas do Diário de Lembranças, a viscondessa fala das visitas em sua casa, que eram muitas, das idas e vindas entre suas três fazendas, Monte Alegre, Piedade e Freguesia, das doenças de parentes, agregados e dos próprios escravos, do colégio dos filhos (Vasconcelos, 2014), entre outros assuntos, como pequenas viagens que faz à Corte do Rio de Janeiro, ou a uma estação de águas em Caxambu, momentos em que seus relatos distanciam-se do cotidiano, para dar lugar a uma observadora mais atenta ao que se passa a sua volta.

Com relação às viagens, assunto que tem certa relevância no diário da viscondessa e que também a condessa de Barral possuía um diário apenas para os registros de viagens, Gómez (2014) observa que as movimentações e os deslocamentos para outros

Rev. Caminhos da Educação: diálogos, culturas e diversidades, Teresina, v. 2, n. 1, p.109-123, mai./ago. 2020 
lugares constituem-se em uma das fontes de onde se tem muitas notícias registradas em diários pessoais.

Em comum as duas mulheres têm o fato de, seja por sua condição de pertencentes à nobreza em um mundo que se republicanizava, seja por sua condição feminina, terem sido silenciadas na história recente, silenciando com elas uma parte importante da história da condição feminina que se pode depreender de seus escritos.

\section{Educadas para gerir a casa, o casamento e os filhos: registros femininos}

Luiza Margarida Portugal de Barros, a condessa de Barral, foi uma representante exemplar da mulher aristocrata e nobre de seu tempo. Nasceu e cresceu em um engenho, e depois da primeira infância, estudou na Europa. Voltou ao Brasil; serviu na Corte Francesa e depois, na brasileira. Transitou com maestria entre dois mundos, 0 arcaico e o moderno. Foi uma das pioneiras em demonstrar independência e audácia ao escolher seu marido, em detrimento daquele escolhido pelo pai. Vivenciou e enfrentou várias revoltas, de escravos no Recôncavo Baiano e de republicanos e anarquistas da França. Ousada também, em defender o abolicionismo. "Costurava" alianças e pensava em dinheiro de forma moderna. Luíza era o casamento de inteligência e espírito e, sobretudo, era extremamente feminina. Del Priore (2008) narra de forma apaixonada, como era o perfil da condessa:

Se suas contemporâneas eram convidadas a obedecer, a manter os olhos baixos, a não fazer perguntas e a não desagradar o sexo oposto, Luisa era o contrário. Dona de personalidade forte, culta, poliglota e elegante, não deixava escolhas: era amada ou detestada. Não se submetia jamais ao despotismo dos homens: nem do pai, nem do marido. Menos ainda ao das mulheres. Sua formação se deu entre os melhores livros e professores, num dos países mais avançados da Europa - a França. Órfã de mãe, muito cedo se aliou ao pai, que the ensinou como funcionava um mundo onde os homens eram reis (Del Priore, 2008, p. 16).

Não apenas por ter uma educação e cultura destacadas entre homens e mulheres de sua época, mas também por ser reconhecida pelo próprio Imperador como uma interlocutora para assuntos relativos à condução do Império, a condessa divergia completamente em seu modo de pensar e proceder, do comportamento e da educação que eram o padrão para a mulher brasileira oitocentista, sobre a qual Vasconcelos (2005) escreve:

Havia ainda alguns críticos para os quais a mulher não deveria exercer qualquer outra função fora do lar doméstico e, portanto, julgavam necessário limitar ao máximo possivel sua educação e direcioná-la apenas para esse fim. Essa facção radicalmente contra a instrução aprimorada da mulher, segundo seus contemporâneos, acabava por impedir que as mães de família fossem melhor educadas para poder fazê-lo com seus próprios filhos (Vasconcelos, 2005, p. 188).

Ainda, discorrendo e analisando a prática educativa oitocentista brasileira, Albuquerque (2015) lembra que Freyre (1997) também delineou o protótipo feminino advindo da educação doméstica, que era utilizado para a maioria das mulheres pertencentes à aristocracia. A condessa modificou e estimulou outra lógica, fazendo com que as famílias nobres, copiando o modelo das princesas, buscassem preceptoras para suas filhas que fossem instruídas $e$, preferencialmente, conhecessem o francês, modelo de civilidade da época.

[...] as preceptoras que os senhores de engenho mais ortodoxamente patriarcais da época - os que, não enviando as filhas para internatos das cidades, desejavam instruí-las em casa-anunciavam, nos jornais, precisarem para encarregarem-se de tal ensino, eram senhoras que soubessem iniciar as meninas no conhecimento da gramática portuguêsa, de geografia, da música, do piano; e que, também, as instruísse no conhecimento da língua francesa: não só no traduzir como no falar dessa língua (Freyre apud Albuquerque, 2015, p.13).

Rev. Caminhos da Educação: diálogos, culturas e diversidades, Teresina, v. 2, n. 1, p.109-123, mai./ago. 2020 


\section{Duas mulheres educadas no oitocentos: registros em egodocumentos femininos}

No período em que foi preceptora das princesas Isabel e Leopoldina, a condessa tornou-se um parâmetro do ideal de "governess", dedicada à educação das principais personagens femininas que iriam atuar e conduzir as circunstâncias sociais, econômicas e políticas do devir na história do Brasil. Ora, tal missão não poderia ser confiada a alguém que não estivesse à altura da responsabilidade que este cargo implicava e que, provavelmente, deve ter sido testada por diversas vezes e por pessoas e instituições (com seus interesses diversos), tendo superado a todos e a tudo que estivesse em seu caminho, haja vista a longevidade de sua permanência na condução da educação das princesas.

A condessa encerrou suas atividades relativas à educação formal das princesas Isabel e Leopoldina em outubro de 1864, quando do casamento da princesa Isabel com o conde d'Eu. Luiza chegou ao Rio de Janeiro, para ensinar e cuidar da educação de duas meninas de 10 e 11 anos, respectivamente, mas que não se tratavam de quaisquer crianças, pois eram as herdeiras do trono do Brasil. Oito anos depois, a condessa deixava duas mulheres nobres, casadas, embora continuasse acompanhando, paralelamente, suas vidas.

Os laços que haviam sido feitos na infância, não se desataram. Permaneceram entrelaçados por 35 anos, numa intensa troca de cartas, (algumas visitas e viagens), até o falecimento da condessa, em 1891. Parte dessa história transpôs o tempo através das palavras registradas nos diários e cartas de Luiza, possibilitando que suas memórias, de alguma forma, se perpetuassem e ainda, colaborando significativamente, em parte da escrita dos acontecimentos do Segundo Reinado no Brasil.

No caso da viscondessa, seu diário que chegou até os nossos dias, inicia em $1^{\circ}$ de janeiro e é escrito até 31 de dezembro de 1887. Ela o escreve como se essa fosse uma prática já habitual, apenas registrando as principais informações do dia: "Alzira com D. Sara e os meninos forão a missa. Choveo muito de tarde. Por causa da chuva não fomos jantar no Pantanal" (Diário de Lembranças, $1887,1^{\circ}$ de janeiro de 1887). Tal registro sugere uma atividade já usual diante de um caderno impresso, que continha em suas folhas iniciais e finais, bem como no cabeçalho de todas as páginas relativas aos dias do ano, múltiplas informações significativas para a época, podendo-se inferir que não era o primeiro do gênero a ser usado por Maria Isabel para a sua escrita diária.

Além do mais, para ler a página inicial de um diário, cabe considerar o que Lejeune (1997, p.102) destaca, contrariando as expectativas: "bem poucas escritoras começam se apresentando e fornecendo informações sobre seu ambiente e personalidade. É preciso adivinhar". No caso da viscondessa, as adivinhações necessárias para situar o seu diário são muitas, contudo, também são muitas as pistas deixadas por outros documentos que confrontados ao diário podem fornecer expressivas informações.

A viscondessa escreve notadamente sobre os acontecimentos diários de sua vida, como quando registra que recebeu uma carta, uma encomenda, suas idas as outras fazendas, suas andanças de "troll", quando todos saem e ela fica sozinha, suas viagens a Corte e outras localidades, quando são pagos os valores que the devem, quando ela paga os escravos, as compras que faz, as coisas que manda para as fazendas, os participantes das despedidas feitas a ela quando viaja, as visitas que faz e recebe, as mortes que lhe são comunicadas, entre outros. No entanto, são informações objetivas nas quais a sua opinião não é expressa, só ocorrendo o contrário raras vezes, como no

Rev. Caminhos da Educação: diálogos, culturas e diversidades, Teresina, v. 2, n. 1, p.109-123, mai./ago. 2020 
dia 24 de janeiro, quando escreve: "O Castro trocou a parelha de machos e uma besta pela parelha preta do Joãozinho dos encantos. Não achei as bestas bonitas acho que não são tratadas" (Diário de Lembranças, 24 de janeiro de 1887).

Da mesma forma no que se refere aos escritos sobre si, as anotações da viscondessa dificilmente dão a perceber algum julgamento, limitando-se a informações sobre o seu estado de saúde, como na passagem a seguir: "Amanheci doente e passei o dia todo de cama" (Diário de Lembranças, 16 de fevereiro de 1887). Suas emoções relativas aos acontecimentos anotados não são escritas e tão pouco podem ser inferidas, pois a morte de um parente é assinalada tão laconicamente quanto à morte de escravos.

A ausência de escrita sobre si, suas impressões ou sentimentos, confrontada a forma contundente com que demonstra insatisfação nas poucas vezes que o faz, evidencia algo que pode ser interpretado, de acordo com as observações de Lejeune (1997), como decorrente da falta de privacidade, desde o lugar de conservação do diário, apartado da vista de todos, até o cuidado com a sua conservação posterior, o que poderia acarretar a leitura de outros.

Inúmeros nomes passam por suas páginas, especialmente quando se trata de parentes e visitantes, sempre participando de alguma refeição, listados um por um, como nos dias em que ela mesma informa a existência de 30 pessoas para 0 jantar (Diário de Lembranças, 14 de fevereiro de 1887). As relações entre a viscondessa e aqueles sobre os quais escreve, apesar de, muitas vezes, não passarem de referências objetivas sobre a visita, possuem personagens recorrentes, indicando a convivência, como é o caso das noras Alzira e Maria Paula, sobre a qual escreve em 15 de fevereiro, após dias de registros de que ela vinha passando mal, "Maria Paula teve um não sucesso", o que provavelmente indica que ela não estava grávida. Quanto a esse aspecto, é curioso que a nora Alzira seja citada cotidianamente, mas nem uma palavra é dita sobre a sua gravidez, não obstante o nascimento do bebê seja registrado em duas passagens do mês de dezembro, o que sugere não haver expectativas enquanto a criança não nascesse, considerando os abortos e natimortos constantes no período.

Dona Sara, a preceptora de seus filhos Mário e Raul, também é bastante citada em suas atividades cotidianas, mas não há uma palavra sobre seus métodos de ensino, ou mesmo sobre como ocorriam as aulas. Além da preceptora, dos filhos e das noras citadas constantemente, muitas outras pessoas aparecem apenas em uma página durante o ano inteiro, especialmente quando estavam doentes. Esse é um registro permanente sobre as doenças que acometiam os parentes, amigos e vizinhos, as mortes e as missas de exéquias.

Os escravos, por sua vez, aparecem continuamente, seja cantando "Reis", no dia 6 de janeiro, seja sendo registrada a realização de sua "matrícula", além da constante menção à confecção e entrega de roupas e utensílios, bem como a anotação daqueles que nasciam, adoeciam ou morriam. Ainda é assinalada a presença de diversos comerciantes que passam pelas fazendas ou que fazem algum negócio com o marido da viscondessa, demonstrando a dinâmica da rede de sociabilidade que envolvia a família e, especialmente, o trânsito intenso de pessoas que circulavam pela casa, por vezes, permanecendo vários dias.

Em relação à escrita sobre o contexto em que vive, vale destacar o relato da viagem que a viscondessa faz para o Rio de Janeiro, começando no dia 12 de março, em que registra as péssimas condições das estradas e a dependência da situação dos caminhos para dar continuidade ao trajeto. Um registro anterior, de 8 de fevereiro, já dava conta da visita do Barão de Araújo que teria ido "tratar da estrada de ferro daqui a Petrópolis passando por entre rios" (Diário de Lembranças, 8 de fevereiro de 1887).

A prática, comum na época, de ir para uma estação de águas, também é relatada pela viscondessa, em 21 de março, quando deixa a Corte e registra no diário: "partimos para Caxambu", de onde só retornam em 21 de abril. Com ela iam o filho, a nora e dois

Rev. Caminhos da Educação: diálogos, culturas e diversidades, Teresina, v. 2, n. 1, p.109-123, mai./ago. 2020 
Duas mulheres educadas no oitocentos: registros em egodocumentos femininos

escravos. Chama atenção o fato de que, enquanto a passagem dos três custou $109 \$ 500$ rs, a dos escravos, Lucia e Arthur, custou apenas $24 \$ 000$ rs.

Entre passeios e encontros com conhecidos, o que sugere ser a mesma rede de pessoas que fazia semelhante programação, passavam-se os dias na estação de águas, com jogos de víspora à noite e até um baile organizado pelos hóspedes, no qual, registra a viscondessa, "somente 27 mulheres compareceram". Percebe-se, ainda, que às famílias de fazendeiros era costume ter casas na Corte, pois é de lá que a viscondessa parte para sua estação de águas e também é lá que passa muitos dias, registrados com constantes visitas e contra visitas de parentes e amigos, de onde, infere-se, são escritas muitas páginas do diário.

No que diz respeito à última análise elencada neste estudo, trata-se de um dos principais padrões utilizados na escrita do diário da viscondessa, que é a elaboração de listas. Consultando Humberto Eco (2010, p. 113), as listas registradas por Maria Isabel tinham um caráter prático, isto é, uma função "puramente referencial", para nomear e elencar objetos que the pertenciam, sugerindo um aspecto de sua personalidade relacionado ao extremo cuidado com seus bens, incluindo-se aí os escravos, os itens de uso pessoal e da casa, as finanças particulares, as dívidas, os empréstimos, os pagamentos e as contas. O detalhamento proposto nas listas, particularmente dos gastos rotineiros, sugere um zelo e preocupação quase conscientes sobre "a riqueza fugaz", denominação utilizada por Muniz (2005), que envolvia as fazendas de café. No entanto, as cuidadas anotações não foram suficientes para que os bens e a riqueza da viscondessa fossem preservados e ela termina seus dias, viúva, e completamente desprovida de todas as suas riquezas.

\section{Considerações Finais}

No século XIX, no Brasil, entre as mulheres das classes mais abastadas, os pensamentos íntimos eram, na maioria das vezes, quando transformados em palavras, guardados para o confessionário (Freyre, 1997). O diário, embora secreto, podia ser lido ou desvelado, num tempo em que a noção de privacidade era muito diferente da atual. Além disso, ler os segredos femininos era uma forma de proteger as filhas, irmãs, sobrinhas, netas, dos maus pensamentos e da perda da representação de "ingenuidade" que era imposta às mulheres.

Como demonstram as principais características das protagonistas do nosso estudo, a educação recebida visava, especialmente, a preparação para o casamento, para gerir a casa, cuidar do marido e dos filhos. Igualmente, a proximidade com as elites imperiais exigia o domínio dos padrões comportamentais franceses, particularmente, para quem frequentava a Corte Imperial, situada na cidade do Rio de Janeiro, e para quem convivia com os membros da realeza.

Por esse motivo, ao ler o Diário de Lembranças da viscondessa de Arcozelo, pouco contato se tem com Maria Isabel, pois essa deu lugar a uma personagem construída ao longo da vida, tratada pelas próprias netas como "vovó viscondessa" (Castro, 2004, p.36) e impregnada pelas inconstâncias da história que a cercava.

Rev. Caminhos da Educação: diálogos, culturas e diversidades, Teresina, v. 2, n. 1, p.109-123, mai./ago. 2020 
Da mesma forma, ao ler as cartas da condessa de Barral, percebe-se que ela viveu em um mundo diferente do de grande parte da população feminina, que nem sempre tinham sequer permissão de ler e escrever. Além disso, a leitura e a análise das cartas da condessa, aliadas aos documentos existentes nos museus e bibliotecas catalogados no inventário elaborado, permitem um novo olhar sobre as práticas de ensino oitocentistas e, ainda, sobre a forma como foi pensada a educação das princesas imperiais brasileiras.

Não se pode perder de vista que há "problemas históricos insolúveis" que, embora interpretados e analisados ao longo dos anos, jamais serão satisfatoriamente equacionados (Cerqueira, 1963, p.13); "Outros se elucidam com a passagem do tempo"; e alguns, se esclarecem por completo através da descoberta de determinados documentos.

Assim, a pesquisa qualitativa, tendo por fonte principal os egodocumentos recolhidos em arquivos pessoais, possibilitou a realização de um inventário de documentos pertencentes a instituições de guarda e patrimônio, que poderá permitir a outros pesquisadores darem continuidade a aspectos não investigados que estiveram presentes na vida das personagens enfocadas e nas circunstâncias que se constituíram como cenários de suas existências silenciadas durante muito tempo.

\section{Referências}

Albuquerque, S. B. de M. Nas memórias de Aurélia: cotidiano feminino no Rio de Janeiro do século XIX. São Cristóvão: Editora UFS, 2015.

Blas, V. S. Aprender a escribir cartas. Los manuales epistolares en la España contemporánea (1927-1945). Gijón (Asturias): Ediciones Trea, 2003.

Bollmann, S. Las mujeres que leen son peligrosas. Madrid-ES: Maeva Ediciones, 2011 a.

Bollmann, S. Las mujeres que escriben también son peligrosas. Madrid-ES: Maeva Ediciones, $2011 \mathrm{~b}$.

Burke, P. A escrita da História: novas perspectivas. São Paulo: Editora da Universidade Estadual Paulista, 1992.

Castro, M. W. de. No tempo dos barões: histórias do apogeu e decadência de uma família fluminense no ciclo do café. Rio de Janeiro: Bem-te-vi, 2004.

Cerqueira, C. D. Pedro II e a Condessa de Barral não foram amantes. Rio de Janeiro: Biblioteca do Exército Editora, 1963.

Cunha, M. T. S. Diários íntimos de professoras: letras que duram. In: Mignot, A. C. V.; Bastos, M. H. C.; Cunha, M. T. S. Refúgios do eu. Educação, história, escrita autobiográfica. Florianópolis: Mulheres, 2000, pp. 159-180.

Del Priore, M. Condessa de Barral. A paixão do Imperador. Rio de Janeiro: Objetiva, 2008.

Diário de Lembranças da Viscondessa de Arcozelo. Museu Imperial de Petrópolis. Cód. DMI-15, 1887.

Digneffe, F. Do individual ao social: a abordagem biográfica. In: Albarello, L. et al. Práticas e métodos de investigação em ciências sociais. Lisboa: Gradiva, 1997, pp. 203-245.

Eco, H. A vertigem das listas. Rio de Janeiro: Record, 2010.

Freyre, G. Casa-grande \& senzala. 32 ed. Rio de Janeiro: Record, 1997.

Fulbrook, M. \& Rublack, U. In Relation: The 'Social Self' and Ego-Documents. German History, vol. 28, n. 3, set., 2010, pp. 263-272.

Rev. Caminhos da Educação: diálogos, culturas e diversidades, Teresina, v. 2, n. 1, p.109-123, mai./ago. 2020 
Duas mulheres educadas no oitocentos: registros em egodocumentos femininos

Gómez, A. C. Aquí lo hallarán con toda verdad. Diarios personales en la España del Siglo de Oro. In: Vasconcelos, M. C. C.; Cordeiro, V. M. R.; Vicentini, P. P. (org.). (Auto) biografia, literatura e história. Curitiba: CRV, 2014.

Henrique, M. C. Um toque de voyeurismo. O diário de Couto de Magalhães (1880 - 1887). Rio de Janeiro: EdUerj, 2009.

Heymann, L. Q. O lugar do arquivo: a construção do legado de Darcy Ribeiro. Rio de Janeiro: FGV, Faperj, 2012.

Hilsdorf, M. L. S. Escola: fontes para a presença feminina na educação. São Paulo (século XIX): inventário, São Paulo: Centro de Memória da Educação - FEUSP e Plêiade, 1999.

Lejeune, P. Diários de garotas francesas no século XIX: constituição e transgressão de um gênero literário. Cadernos Pagu, n. 8/9, 1997, pp. 99-114.

Magalhães Junior, R. D. Pedro II e a Condessa de Barral. Rio de Janeiro: Editora Civilização Brasileira S/A, 1956.

Muniz, C. M. L. A riqueza fugaz: trajetórias e estratégias de famílias de proprietários de terras de Vassouras, 1820-1890. Tese de Doutorado. Programa de Pós-Graduação em História Social do Instituto de Filosofia e Ciências Sociais da Universidade Federal do Rio de Janeiro, 2005.

Perrot, M. As mulheres ou os silêncios da história. Bauru, SP: EDUSC, 2005.

Pinho, W. Salões e damas do Segundo Reinado. São Paulo: Livraria Martins Editora, 1959.

Rocha, S. R. M. Construção e análise do inventário patrimônio religioso paraibano: informação como representação social. Dissertação de Mestrado em Ciência da Informação da Universidade Federal da Paraíba, João Pessoa, 2011.

Samara, E. M.; Tupy, I. S. S. T. História \& Documento e metodologia de pesquisa. São Paulo: Autêntica, 2010.

Schulze, W. Ego-Dokumente: Annäherung an den Menschen in der Geschichte. Berlin: Akademie Verlag GmbH, 1996.

Vasconcelos, M. C. C. A casa e seus mestres: a educação no Brasil de oitocentos, Rio de Janeiro: Gryphus, 2005.

Vasconcelos, M. C. C. A escrita cotidiana no diário de lembranças da viscondessa de Arcozelo: fragmentos (auto)biográficos de um egodocumento. In: Vasconcelos, M. C. C.; Cordeiro, V. M. R.; Vicentini, P. P. (org.). (Auto) biografia, literatura e história. Curitiba: CRV, 2014, pp. 95-114.

Vasconcelos, M. C. C.; Francisco, A. C. M. Em busca de uma preceptora para a nobreza brasileira: a condessa e o imperador. In: Silva, A. L.; Monti, E. M. G. (org.). Escritas (auto)biográficas e histórias da educação. Curitiba: CVR, 2014, pp. 11-32.

RECEBIDO: 01/06/2020

APROVADO:03/08/ 2020
RECEIVED: 01/06/2020

APPROVED: 03/08/2020
RECIBIDO: 03/08/ 2020

APROBADO: 03/08/ 2020

Rev. Caminhos da Educação: diálogos, culturas e diversidades, Teresina, v. 2, n. 1, p.109-123, mai./ago. 2020 
https://doi.org/10.26694/caedu.v3i1. 10997

ISSN 2675-1496

(c)

Rev. Caminhos da Educação: diálogos, culturas e diversidades, Teresina, v. 2, n. 1, p.109-123, mai./ago. 2020 